\title{
Paisaje de varones. Genealogías del homoerotismo en la literatura argentina
}

Peralta, Jorge (2017)

Barcelona: Icaria, $190 \mathrm{pp}$.

\section{(4) Marcos Zangrandi UBA-UNA-CONICET}

¿Son los escondrijos secretos de los parques, las garçonnières, los baldíos desolados, las habitaciones de las pensiones, edificantes de las sexualidades? ¿Pueden estos territorios, inscriptos en distintas ficciones argentinas, ayudar a comprender la construcción de deseos desalineados de las normativas sociales? Estas preguntas motivan la investigación de Jorge Peralta en Paisaje de varones, libro que indaga en los lazos posibles entre la configuración de los espacios que surgen de distintas narraciones argentinas de la primera mitad de siglo XX y las escenas de encuentros -de diferente intensidad y cualidad- entre varones.

Como punto de partida, Peralta formula algunas premisas iniciales. Primero, que los sujetos erigen los espacios en la misma relación en que los espacios constituyen a los sujetos. Contiguamente, que en la diversidad espacial se ponen de manifiesto formas de opresión y de resistencia de prácticas sexuales. Finalmente, que el concepto de "espacio homoerótico" expande las perspectivas de investigación, a diferencia de "homosexual", "queer" o "gay", términos más bien ligados a las identidades que se asentaron en las últimas décadas del siglo XX.

De acuerdo con esto, Paisaje de varones plantea un recorrido inusual, que esquiva una historización cronológica y evita los jalones que rodean expresamente la configuración de la "homosexualidad" en la narrativa argentina (asentados, principalmente, en Correas, Pellegrini y Puig). El texto, en cambio, examina algunos hitos significativos y menos explorados del “espacio homoerótico", en los cuales se aprecian no solo los andamiajes preliminares de los deseos y las corporalidades disidentes, sino también las formas sociales y culturales con las que ellos dialogan.
El capítulo inicial de Paisaje de varones está dedicado a estudiar propuestas teóricas sobre el espacio. El autor recoge, principalmente, dos formulaciones. En primer lugar, el concepto de "heterotopías" de Michel Foucault, en tanto contra-emplazamientos, territorios diferentes o inversiones de los lugares instituidos por la sociedad. Luego, los "espacios sociales" de Henri Lefevre, zonas que responden a la producción social, generadas mediante prácticas espaciales específicas, representaciones del espacio y espacios de representación, a los que corresponderían, respectivamente, las formas de un plano percibido, concebido y vivido. A partir de estos conceptos, Peralta da forma al concepto capital de su trabajo, el "espacio homoerótico”, que tendría como características, entre otras, la transgresión y la apropiación territorial (esto es, la posibilidad de subvertir y contradecir la función de los lugares), la invisibilidad, la sectorialización y la fluidez espacial. A continuación, Paisaje de varones propone un recorrido genealógico por algunos textos clásicos de la literatura argentina, a la manera de "eslabones" que ofrecen una panorámica preliminar de vínculos homoeróticos y su relación con la dimensión espacial. Algunas de esas piezas -El matadero, de Esteban Echeverría, Martín Fierro, de José Hernández, En la sangre, de Eugenio Cambaceres y Las fuerzas extrañas, de Leopoldo Lugones- estarían signados por un gesto "esquivo" (y, en este sentido, por operaciones de elipsis espaciales) hacia la disidencia y señalarían, de modo sugerido, una "otredad".

En los capítulos siguientes, el libro hace su apuesta central respecto de las modalidades en que los "espacios homoeróticos" maniobraron en la literatura argentina. En el primero, "Mapas fundacionales", Peralta se enfoca en algunos textos de las primeras décadas del siglo XX alrededor de la hipótesis del 
libro: el drama Los invertidos (1914) de José González Castillo, el cuento "Riverita" (1925) de Roberto Mariani, el clásico El juguete rabioso (1926) de Roberto Arlt y la novela Reina del Plata (1946) de Bernardo Kordon. Paisaje de varones examina en ellos la relación entre los espacios representados y el deseo entre los personajes varones, en diálogo con la trama política y cultural de cada instancia -adversa, sí, pero no idéntica-. Como inicio, el análisis de Los invertidos echa luz sobre el lazo entre la relación homoerótica entre dos personajes principales y los lugares en que se desarrolla la obra, en particular sobre el contrapunto entre la casa burguesa, eje de la virtud (aunque también de los dobleces sociales), y la garçonnière o piso de soltero, espacio del secreto y de la transgresión, en el que, además de transformarse en un territorio alternativo que reúne deseos, cuerpos e identidades disidentes, incorpora referencias veladas hacia otros circuitos urbanos de "yiro" y de encuentros entre hombres.

Los espacios homoeróticos de la narrativa de los años veinte, en cambio, se desplazan hacia zonas compartidas y de menor rango social, como es el caso de la oficina de "Riverita", de Mariani, y de la pensión de El juguete rabioso, de Arlt. Estos escenarios plebeyos posibilitan enclaves -el después de hora en la oficina; la debilidad de la privacidad en la pensión- para lazos íntimos y evidentemente ambiguos entre varones. La novela de Kordon, finalmente, ubica el espacio homoerótico en el exterior, los bosques de Palermo; allí se identifican los recorridos, las prácticas, los gestos del "levante" y, al mismo tiempo, la violencia hacia los cuerpos que transitan en las zonas "peligrosas", de acuerdo al riesgo y la frontera sociopolítica que presumen -son conocidas las razzias policiales hacia homosexuales durante la época peronista-. Reina del Plata es un texto significativo, en este sentido, no solo porque incorpora un espacio homoerótico que se escapa de la reclusión (y desde allí del secreto, de lo que no "osa decir su nombre"), sino también porque muestra, a partir de los encuentros sexuales entre hombres, un borde franqueable que atraviesa políticas y grupos sociales. "La narración de la historia", aquel relato de Carlos Correas de 1959, clave en relación con la figuración de la homosexualidad en la literatura argentina, no parece estar lejos de este texto de Bernardo Kordon.
El capítulo "Homotextualidades" realiza un giro en el análisis, ya que indaga no ya sobre la configuración de zonas de encuentros eróticos entre varones, sino en de "espacios homoeróticos retóricos". Esto es, "espacios, entendidos aquí en su estricta materialidad textual (...); retóricos, por cuanto representan un esfuerzo expresivo particular, cuya eficacia depende de una adecuada manipulación de los significados que se buscan connotar"(P. 125). A partir de esta definición, Peralta estudia Álamos talados (1942) de Abelardo Arias, Las ratas: Sombras suele vestir, (1943), de José Bianco, Los ídolos (1953) y El retrato amariIlo (1956), de Manuel Mujica Lainez, textos que, de acuerdo a su corte temporal, literario y sociocultural, constituyen un conjunto nítido y relativamente homogéneo. Estas narraciones operarían a partir de estrategias de enmascaramiento y de códigos de supuestos (la ambigüedad, el secreto, el límite frente al cual se detiene el relato, los intermediarios, las suspicacias) y constituirían una arquitectura simbólica del deseo disidente asentado sobre los intersticios y los refugios de sentido que permite el lenguaje. Vale destacar, en este capítulo, el rescate de Ser un hombre como tú (1957) de Juan Arias, pieza de teatro que cuenta el drama de un homosexual de provincia frente a la intolerancia de su familia. Este texto, nunca representado y muy poco conocido, además de señalar la homofobia -asentada aquí en el odio fraternal-, es una bisagra en la construcción de la homosexualidad en Argentina, desde la vergüenza y desgracia familiar de Los invertidos, a la asunción de una identidad homosexual que se forja en la segunda mitad del siglo XX.

Las virtudes de Paisaje de varones residen tanto en su planteo analítico y conceptual como en sus valiosos hallazgos de archivo. Lejos de todo esencialismo, la figura central del vínculo homoerótico y las categorías espaciales le permiten a Peralta trabajar en una perspectiva novedosa, flexible y rica. De acuerdo con todo esto, la genealogía que traza este libro resulta una contribución notable para la investigación en sexualidades que, a la vez, profundiza y redimensiona las tramas de la literatura y de la cultura argentinas del siglo XX. 